\title{
Reproducibility of different screening classifications in ultrasonography of the newborn hip
}

\author{
Christian D Peterlein ${ }^{1 *}$, Karl F Schüttler ${ }^{1}$, Stefan Lakemeier ${ }^{1}$, Nina Timmesfeld ${ }^{2}$, Christian Görg ${ }^{3}$, \\ Susanne Fuchs-Winkelmann", Markus D Schofer ${ }^{1}$
}

\begin{abstract}
Background: Ultrasonography of the hip has gained wide acceptance as a primary method for diagnosis, screening and treatment monitoring of developmental hip dysplasia in infants. The aim of the study was to examine the degree of concordance of two objective classifications of hip morphology and subjective parameters by three investigators with different levels of experience.

Methods: In 207 consecutive newborns (101 boys; 106 girls) the following parameters were assessed: bony roof angle ( $\alpha$-angle) and cartilage roof angle ( $\beta$-angle) according to Graf's basic standard method, "femoral head coverage" (FHC) as described by Terjesen, shape of the bony roof and position of the cartilaginous roof. Both hips were measured twice by each investigator with a $7.5 \mathrm{MHz}$ linear transducer (SONOLINE G60S ${ }^{\circledR}$ ultrasound system, SIEMENS, Erlangen, Germany).

Results: Mean kappa-coefficients for the subjective parameters shape of the bony roof (0.97) and position of the cartilaginous roof (1.0) demonstrated high intra-observer reproducibility. Best results were achieved for $\alpha$-angle, followed by $\beta$-angle and finally FHC. With respect to limits of agreement, inter-observer reproducibility was calculated less precisely.
\end{abstract}

Conclusions: Higher measurement differences were evaluated more in objective scorings. Those variations were observed by every investigator irrespective of level of experience.

\section{Background}

Since its introduction in 1980, ultrasonography (US) of the newborn hip has gained widespread acceptance in the screening and diagnosis of developmental hip dysplasia (DDH) [1-5]. Over time, various screening methods and classifications were developed. The most widely used method of evaluating ultrasonograms in newborns is the measurement of the bony roof angle ( $\alpha$-angle) and the cartilage roof angle ( $\beta$-angle) according to Graf [6-8]. However, some investigators demonstrated that these methods were susceptible to measurement errors, particularly in newborns $[9,10]$. A technique based on

\footnotetext{
* Correspondence: peterlei@med.uni-marburg.de

'Department of Orthopaedics and Rheumatology, University Hospital

Giessen and Marburg, Marburg, Germany

Full list of author information is available at the end of the article
}

the measurement of distances was later developed by Terjesen [11,12] and Morin [13].

Discrepancy in measurement may be due to the variability in the US examination itself and in its interpretation. Studies demonstrated that both the performance of US and its interpretation influence the results and potential treatment $[10,14-16]$. The aim of our study was to analyze the reproducibility of two objective classifications and descriptive parameters in newborn hip US and the influence of investigators' level of experience. Unlike in other studies, all three investigators both performed the US and provided the interpretation of their own images in a blinded fashion.

\section{Methods}

The hips of 207 consecutive newborns (101 boys, 106 girls) were prospectively screened. The study was 
conducted in accordance with the Declaration of Helsinki and approved by the ethics committee of the University of Marburg, Germany. Informed consent was obtained from both parents. US was performed on each newborn by three investigators with different levels of experience - an experienced paediatric orthopaedic surgeon (CP), a senior orthopaedic surgeon (MS), and a trained medical student (KS). The former two investigators attended several formal US training courses. The medical student attended basic US training and theoretical lessons on Graf's and Terjesen's techniques. We used a mobile SONOLINE G60S ${ }^{\odot}$ ultrasound system (SIEMENS, Erlangen, Germany), equipped with a $7.5 \mathrm{MHz}$ linear array probe. According to Graf, newborns up to week 4 of life should be examined with a linear transducer with a minimum frequency of $7.5 \mathrm{MHz}$, for precise measurement of small anatomical structures [17]. The software of the SONOLINE G60S ${ }^{\oplus}$ produces a standard projection of the image, which can be viewed and interpreted in the anterior-posterior view, as if on a plain radiograph. Adjustments in processing had been previously carried out by the Head of the Ultrasound Laboratory (CG).

Both hips were measured twice by each investigator. The examination was conducted in an infant bassinet, which allowed for standardized positioning and scanning. According to Graf, standard images through the deepest part of the acetabulum were obtained in the coronal plane. The three landmarks were considered: the lower limb of the os ilium, the mid portion of the acetabular roof, and the labrum. The pictures were stored on the SONOLINE G60S ${ }^{\circ}$ hard drive, and then printed on high-quality paper strips (thermal paper K65HM-CE, Mitsubishi, Japan) by a statistician (NT) who was not involved in the examinations. The strips were randomized to generate blinded conditions. Each investigator independently evaluated his own hard-copy strips 4 weeks later. Measurements were performed manually. In a standardized manner, two descriptive parameters - the shape of the bony roof and the position of the cartilaginous roof - were assigned first (Figure 1). After drawing a reference line, two parallel lines, (a) from the acetabular floor to the reference line, and (b) from the same point on the acetabular fossa to the most lateral part of the cartilaginous femoral head were marked (Figure 2). The distances were measured in millimeters, and femoral head coverage according to Terjesen $[11,12]$ was calculated by the formula $a / b \times$ $100 \%$. Finally, the bony roof angle ( $\alpha$-angle) and the cartilage roof angle $(\beta$-angle) were measured $[7,8]$ (Figure $3)$. Thus, each investigator examined a total of 414 hips (828 hard copy strips). Examiners did not observe each other nor did they communicate about their interpretations until the end of the study.

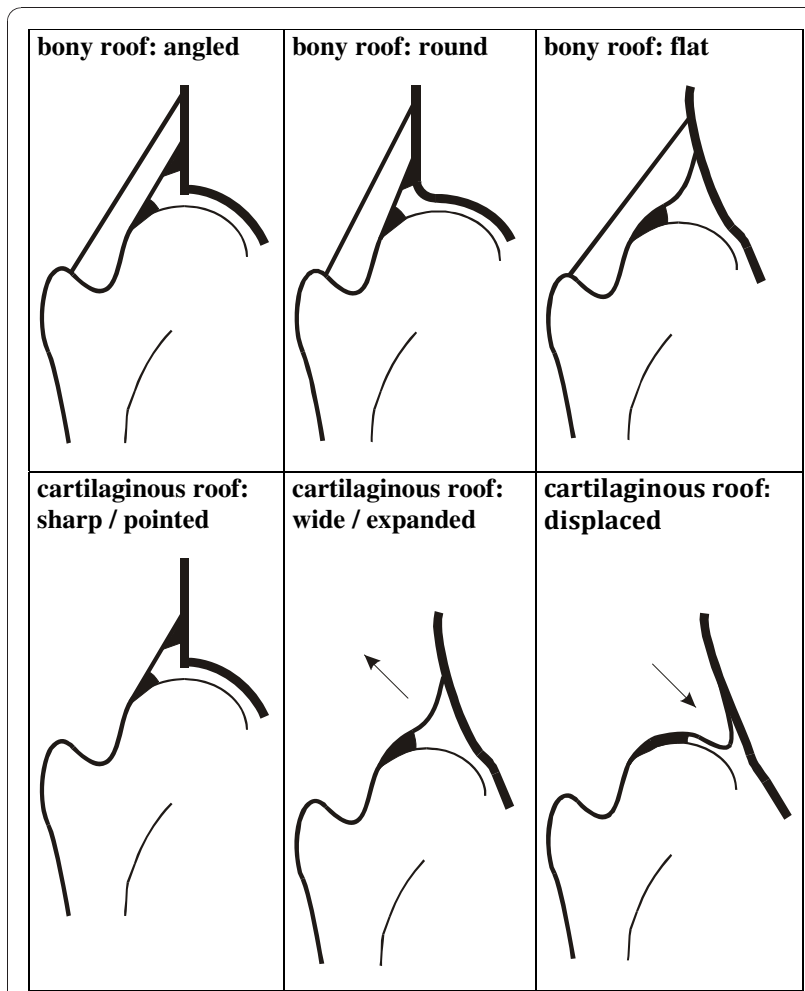

Figure 1 Characterization of descriptive parameters

\section{Statistical analysis}

The mean of the 6 observations from each hip was computed for $\alpha$ - and $\beta$-angle and femoral head coverage

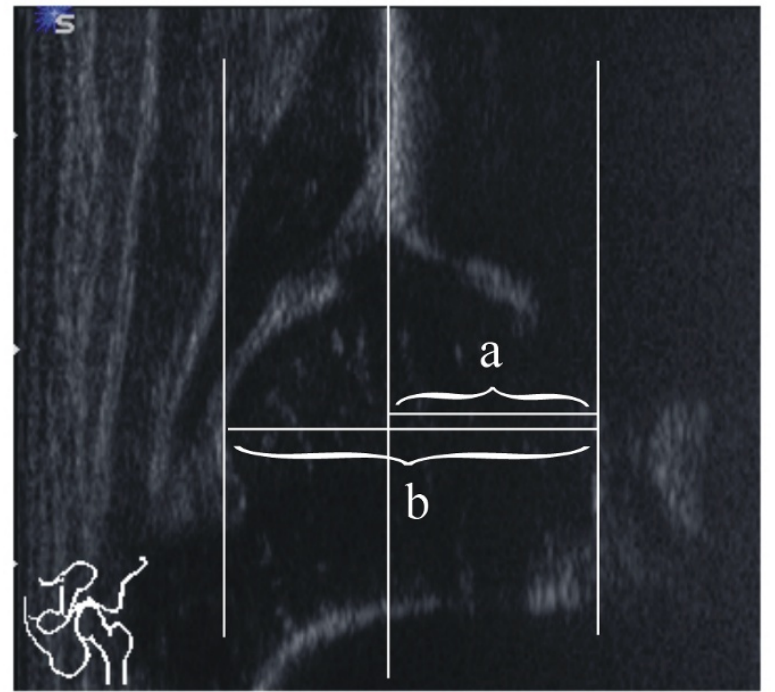

Figure 2 Measurement of the femoral head coverage (FHC) 


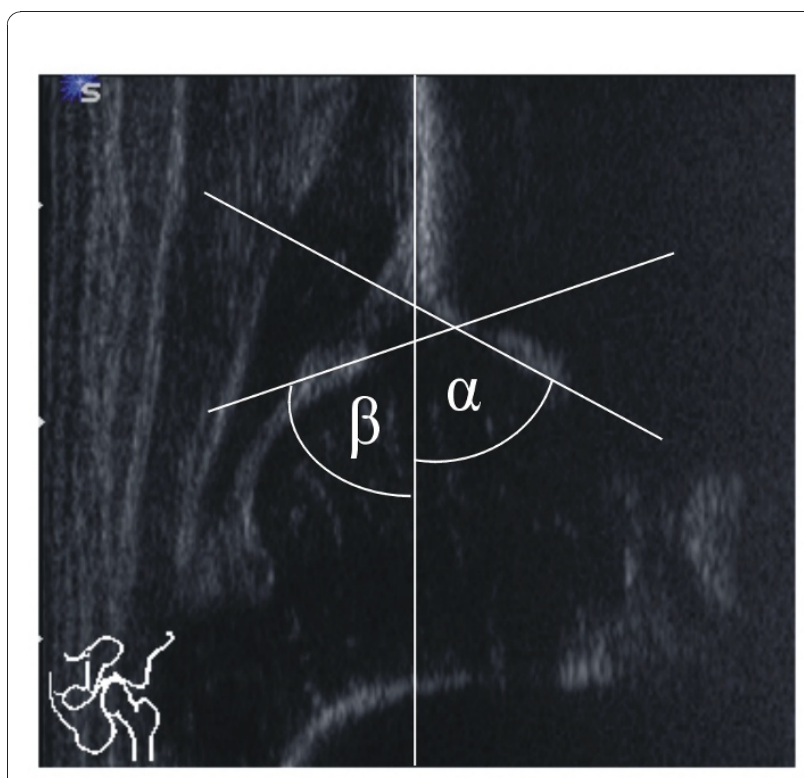

Figure 3 Measurement of the $\alpha$ - and $\beta$-angle.

(FHC) and hips were thus classified. As in previous studies $[18,19]$ hip types were combined to form 4 main groups: type I = normal; type IIa = immature; type IIc/D $=$ minor dysplasia; and types III/IV = major dysplasia. For the continuous outcomes, $\alpha$ - and $\beta$-angle and femoral head coverage (FHC), intra-observer agreement was obtained by the mean difference between two series of measurements and related limits of agreement [20]. Inter-observer agreement between two observers was measured by mean difference and general limits of agreement [21].

For nominal outcomes, such as shape of the bony roof and position of the cartilaginous roof, Cohen's kappa coefficient and the percentage of agreement were computed for both intra- and inter-observer agreement. For inter-observer agreement between two observers, the mean of Cohen's kappas, obtained from the four pairs of measurements, was calculated. Inter-observer agreement between all three observers was measured by the mean of Light's kappas, obtained from the nine combinations. Similarly, the percentages of agreement were calculated. All computations were done by statistical software R [22].

\section{Results}

207 consecutive newborns (101 male, 106 female) were screened, at an average age of 2.64 days of life (range 1 8 days). A total of 2484 hard copy strips were evaluated. The mean $\alpha$-angle was $64.9^{\circ}\left( \pm 3.7^{\circ}\right.$; range $\left.46.3^{\circ}-75.2^{\circ}\right)$, the mean $\beta$-angle was $61.4^{\circ}\left( \pm 4.8^{\circ}\right.$; range $\left.50.5^{\circ}-91.3^{\circ}\right)$, and the mean femoral head cover value (FHC) was $61.4 \%$
( $\pm 5.0 \%$; range $49.4 \%-90.8 \%$ ). In the male study population the mean $\alpha$-angle was $65.9^{\circ}\left( \pm 3.3^{\circ}\right.$; range $55.0^{\circ}$ $\left.-75.2^{\circ}\right)$, the mean $\beta$-angle was $60.3^{\circ}\left( \pm 4.1^{\circ}\right.$; range $50.5^{\circ}$ $\left.-74.2^{\circ}\right)$, and the FHC was $60.3 \%$ ( $\pm 4.4 \%$; range $49.4 \%$ $74.4 \%)$. The female study population demonstrated an average $\alpha$-angle of $63.9^{\circ}\left( \pm 3.8^{\circ}\right.$; range $\left.46.3^{\circ}-72.8^{\circ}\right)$, $\beta$-angle of $62.4^{\circ}\left( \pm 5.2^{\circ}\right.$; range $\left.51.7^{\circ}-91.3^{\circ}\right)$, and FHC value of $62.5 \%$ ( $\pm 5.2 \%$; range $51.6 \%-90.8 \%$ ). Both the $\alpha$-angle and the FHC demonstrated a significant difference between sexes $\left(\mathrm{p}<10^{-7}\right.$ and $\left.\mathrm{p}<10^{-5}\right)$. There was no statistically significant difference between the left and the right hips. Terjesen defined hips with femoral head cover $<47 \%$ (male) and $<44 \%$ (female) as pathological. These values were not measured in our cohort. According to Graf's classification, 31 hips $(7.5 \%)$ were immature $(n=31)$ and one hip (0.2\%) dysplastic (Additional file 1).

\section{Objective scorings}

The best results with respect to limits of agreement were achieved for the $\alpha$-angle (mean range: $-5.12-+5.61$ ), followed by the $\beta$-angle (mean range: $-10.12-+10.09$ ), and finally for FHC (mean range: $-10.52-+11.03)$. The experienced pediatric orthopaedic surgeon achieved the most accurate reproducibility of the Graf classification. The Terjesen classification was reproduced most accurately by the medical student (Additional file 2). For all parameters, the inter-observer reproducibility was calculated as less precise; those variations were observed in all three investigators, irrespective of level of experience. The kappa statistics indicated moderate agreement.

\section{Descriptive scorings}

The mean kappa-coefficients for the subjective parameters, shape of the bony roof (0.97) and position of the cartilaginous roof (1.0), demonstrated high intraobserver reproducibility (Additional file 3 ). For all parameters, the inter-observer reproducibility was calculated as less precise.

\section{Discussion}

This study was conducted to compare the reproducibility of the Graf and Terjesen methods and to analyze the value of descriptive parameters in newborn hip US. Sonographic measurements of anatomical specimens in a water bath demonstrated comparable reproducibility for the two methods [23] but only a few clinical studies have been published to date [24-26]. Czubak [25] and Falliner [24] found a significant correlation ( $p<0.01$ ) between the $\alpha$-angle and the FHC. Unlike in our study, the $\beta$-angle was not measured and the authors calculated contradictory results. Falliner scored $4.1 \%$ of the hips as dysplastic according to Terjesen, and 1.2\% according to Graf; Czubak found 29\% of 657 hips to be "immature" according to Graf, and 14\% "suspected 
dysplastic" according to Terjesen. The definition of pathological hips in measurement techniques, based on the calculation of distances, is inconsistent [11-13]. Assuming that hips with $\mathrm{FHC}<47 \%$ (male) and $<44 \%$ (female) are pathological, no one in our cohort was affected. Our results, with respect to the Graf $(7.5 \%$ immature and $0.2 \%$ dysplastic) better match the reported frequency of hip dysplasia in Europe [27-29].

The correlation coefficients and the limits of agreement for the measured bony roof angle ( $\alpha$-angle) in our study closely correlate with those found by Roovers [18] and Simon [19]. Dias [30], Bar-On [14], and Ömeroglu [31] published better results for the kappa coefficients. However, unlike in our study, hips were classified as simply "normal" and "abnormal." Since the kappa coefficients depend on true prevalences, studies can only be correctly compared if there is agreement among the group categories.

Further studies demonstrated that examiners tend to report higher variations when determining $\beta$-angle compared with $\alpha$-angle $[15,16,32]$. This variance is also observed when the angles are measured by the same investigator. In our study, we found no large systematic differences in $\alpha$-angle and $\beta$-angle measurements between the three observers. The relatively high variability of the measured $\beta$-angles in our study supports the findings of others $[10,14,15,32]$.

Simon evaluated inter-observer agreement of the Graf classification between a radiology team, orthopaedists, registrars and paediatricians. The four groups were not present when the images were obtained and blinded with respect to anamnesis and clinical examination of the infants. Greatest agreement existed between the paediatricians and the orthopaedists. The authors explained this result by the long-term-experience in these physicians in US.

Unlike previously described studies, the three investigators in this study both performed US on the newborns and analyzed their own results in a blinded fashion. We found no statistically significant difference between investigators' measurements. This was unexpected, since the paediatric orthopaedic surgeon $(\mathrm{CP})$ conducts more than 1000 hip US examinations per year and the medical student (KS), none.

For the parameters shape of the bony roof and position of the cartilaginous roof, kappa statistics indicate excellent intra- and inter-observer agreement. This might be explained by the fact that all investigators, irrespective of their level of experience in clinics, were trained in checking the "principles of the standard plane" accurately lower limb of the bony ileum in the depth of the acetabular fossa, mid portion of the acetabular roof, and acetabular labrum. However, standardized anatomical identification in US is mandatory. According to Graf, this includes determination of the chondroosseous junction (epiphyseal plate of the femur), femoral head, synovial fold, and joint capsule.

The correct order of the anatomical identification of the newborn hip US is taught in training courses. Hell recently assessed inter- and intra-observer reliability and learning curves in participants after basic, advanced, and final courses in hip US using the Graf method. Improvements in reproducibility gradually occurred in course participants. Measurement discrepancies were seen, particularly in abnormal and poor quality US examinations, and in the measurement of the $\beta$-angle $[32,33]$.

There were several limitations to our study. Only one dysplastic hip was found in the study group. Thus, the data lacks reliability for abnormal hips and requires a larger sample size. Moreover, the rapid measurement schedule is prone to induce errors due to resistive newborns, malposition, or tilting of the probe.

\section{Conclusions}

US is a sensitive diagnostic tool in detection and management of DDH. Our study demonstrates that, irrespective of investigator experience, an adequate degree of inter-and intra-observer reliability can be obtained for both objective and descriptive parameters. A standardized method of anatomical identification of landmarks is mandatory.

\section{Additional material}

Additional file 1: Distribution of 414 US examinations (mean of 6 observations from each hip), according to Graf.

Additional file 2: Intra- and inter-observer results of objective parameters (mean difference and limits of agreement, in parentheses).

Additional file 3: Intra- and inter-observer results of subjective parameters (mean difference and limits of agreement, in parentheses)

\section{Acknowledgements}

No funding or external support was received by any of the authors in support of or in any relationship to the study.

\section{Author details}

'Department of Orthopaedics and Rheumatology, University Hospital Giessen and Marburg, Marburg, Germany. ${ }^{2}$ Institute of Medical Biometry and Epidemiology, Philipps University Marburg, Germany. ${ }^{3}$ Department of Interna Medicine, Ultrasound-Laboratory, University Hospital Giessen and Marburg, Marburg, Germany.

\section{Authors' contributions}

Ultrasonography was performed by CDP, KFS and MDS. The initial draft was written by CDP. CG, SL and SFW contributed equally to this work: they advised in the developing of the study protocol and critically revised the manuscript. NT performed data collection, analysis and statistics. All authors participated in the reviewing process and approved the final manuscript.

Competing interests

The authors declare that they have no competing interests. 
Received: 2 August 2010 Accepted: 24 December 2010

Published: 24 December 2010

\section{References}

1. Riboni G, Bellini A, Serantoni S, Rognoni E, Bisanti L: Ultrasound screening for developmental dysplasia of the hip. Pediatr Radiol 2003, 33:475-481.

2. Shipman SA, Helfand M, Moyer VA, Yawn BP: Screening for developmental dysplasia of the hip: a systematic literature review for the US Preventive Services Task Force. Pediatrics 2006, 117:e557-576.

3. Roposch A, Wright JG: Increased diagnostic information and understanding disease: uncertainty in the diagnosis of developmental hip dysplasia. Radiology 2007, 242:355-359.

4. Toma P, Valle M, Rossi U, Brunenghi GM: Paediatric hip-ultrasound screening for developmental dysplasia of the hip: a review. Eur $J$ Ultrasound 2001, 14:45-55.

5. Rosendahl K, Toma P: Ultrasound in the diagnosis of developmental dysplasia of the hip in newborns. The European approach. A review of methods, accuracy and clinical validity. Eur Radiol 2007, 17:1960-1967.

6. Graf R: The diagnosis of congenital hip-joint dislocation by the ultrasonic Combound treatment. Arch Orthop Trauma Surg 1980, 97:117-133.

7. Graf R: Classification of hip joint dysplasia by means of sonography. Arch Orthop Trauma Surg 1984, 102:248-255.

8. Graf R: [Hip ultrasonography. Basic principles and current aspects]. Orthopade 1997, 26:14-24.

9. Niethard FU, Roesler H: [Accuracy of length and angle measurements in the roentgen image and sonogram of the pediatric hip joint]. Z Orthop Ihre Grenzgeb 1987, 125:170-176.

10. Zieger M, Wiese H, Schulz RD: [Value of angle measurements in hip sonography. Methodological and technical analysis]. Radiologe 1986, 26:253-256.

11. Terjesen $\mathrm{T}$ : Ultrasound as the primary imaging method in the diagnosis of hip dysplasia in children aged < 2 years. J Pediatr Orthop B 1996, 5:123-128

12. Terjesen T, Bredland T, Berg V: Ultrasound for hip assessment in the newborn. J Bone Joint Surg [Br] 1989, 71:767-773.

13. Morin C, Harcke HT, MacEwen GD: The infant hip: real-time US assessment of acetabular development. Radiology 1985, 157:673-677.

14. Bar-On E, Meyer S, Harari G, Porat S: Ultrasonography of the hip in developmental hip dysplasia. J Bone Joint Surg [Br] 1998, 80:321-324

15. Rosendahl K, Aslaksen A, Lie RT, Markestad T: Reliability of ultrasound in the early diagnosis of developmental dysplasia of the hip. Pediatr Radiol 1995, 25:219-224.

16. Roovers EA, Boere-Boonekamp MM, Castelein RM, Zielhuis GA, Kerkhoff TH: Effectiveness of ultrasound screening for developmental dysplasia of the hip. Arch Dis Child Fetal Neonatal Ed 2005, 90:F25-30.

17. Graf R: Hip Sonography: Diagnosis and Management of Infant Hip Dysplasia. Springer, Berlin; 2006.

18. Roovers EA, Boere-Boonekamp MM, Geertsma TS, Zielhuis GA, Kerckhoff AH: Ultrasonographic screening for developmental dysplasia of the hip in infants. Reproducibility of assessments made by radiographers. $J$ Bone Joint Surg [Br] 2003, 85:726-730

19. Simon EA, Saur F, Buerge M, Glaab R, Roos M, Kohler G: Inter-observer agreement of ultrasonographic measurement of alpha and beta angles and the final type classification based on the Graf method. Swiss Med Wkly 2004, 134:671-677.

20. Bland JM, Altman DG: Statistical methods for assessing agreement between two methods of clinical measurement. Lancet 1986, 1:307-310.

21. Carstensen B, Simpson J, Gurrin LC: Statistical Models for Acessing Agreement in Method Comparision Studies with Replicate Measurements. The International Journal of Biostatistics 2008, 4(1):16

22. Team RDC. R: A language and environment for statistical computing. Vienna 2008

23. Falliner A, Hahne HJ, Hedderich J, Brossmann J, Hassenflug J: Comparable ultrasound measurements of ten anatomical specimens of infant hip joints by the methods of Graf and Terjesen. Acta Radiol 2004, 45:227-235.

24. Falliner A, Schwinzer D, Hahne HJ, Hedderich J, Hassenflug J: Comparing ultrasound measurements of neonatal hips using the methods of Graf and Terjesen. J Bone Joint Surg [Br] 2006, 88:104-106.

25. Czubak J, Kotwicki T, Ponitek T, Skrzypek H: Ultrasound measurements of the newborn hip. Comparison of two methods in 657 newborns. Acta Orthop Scand 1998, 69:21-24.
26. Irha E, Vrdoljak J, Vrdoljak O: Evaluation of ultrasonographic angle and linear parameters in the diagnosis of developmental dysplasia of the hip. J Pediatr Orthop B 2004, 13:9-14.

27. Vencalkova S, Janata J: [Evaluation of screening for developmental dysplasia of the hip in the Liberec region in 1984-2005]. Acta Chir Orthop Traumatol Cech 2009, 76:218-224.

28. von Kries R, lhme N, Oberle D, Lorani A, Stark R, Altenhofen L, Niethard FU: Effect of ultrasound screening on the rate of first operative procedures for developmental hip dysplasia in Germany. Lancet 2003, 362:1883-1887.

29. Wirth T, Stratmann L, Hinrichs F: Evolution of late presenting developmental dysplasia of the hip and associated surgical procedures after 14 years of neonatal ultrasound screening. J Bone Joint Surg [Br] 2004, 86:585-589.

30. Dias JJ, Thomas IH, Lamont AC, Mody BS, Thompson JR: The reliability of ultrasonographic assessment of neonatal hips. J Bone Joint Surg $[B r]$ 75:479-482.

31. Omeroglu H, Bicimoglu A, Seber S: Assessment of variations in the measurement of hip ultrasonography by the Graf method in developmental dysplasia of the hip. J Pediatr Orthop B 2001, 10:89-95.

32. Hell AK, Becker JC, Ruhmann O, Lewinski G, Lazovic D: [Inter- and intraobserver reliability in Graf's sonographic hip examination]. Z Orthop Unfall 2008, 146:624-629.

33. Graf R: [Ultrasonography-guided therapy]. Orthopade 1997, 26:33-42.

Pre-publication history

The pre-publication history for this paper can be accessed here: http://www.biomedcentral.com/1471-2431/10/98/prepub

doi:10.1186/1471-2431-10-98

Cite this article as: Peterlein et al: Reproducibility of different screening classifications in ultrasonography of the newborn hip. BMC Pediatrics 2010 10:98

\section{Submit your next manuscript to BioMed Central and take full advantage of:}

- Convenient online submission

- Thorough peer review

- No space constraints or color figure charges

- Immediate publication on acceptance

- Inclusion in PubMed, CAS, Scopus and Google Scholar

- Research which is freely available for redistribution
C Biomed Central 